\title{
Optimizing bulk milk dioxin monitoring based on costs and effectiveness
}

\author{
V. H. Lascano-Alcoser, ${ }^{* 1}$ A. G. J. Velthuis, ${ }^{*}$ H. J. van der Fels-Klerx, $†$ L. A. P. Hoogenboom, $\dagger$ \\ and A. G. J. M. Oude Lansink* \\ *Business Economics, Wageningen University, Hollandseweg 1, $6706 \mathrm{KN}$, Wageningen, the Netherlands \\ †RIKILT-Institute of Food Safety, Wageningen University and Research Center, Akkermaalsbos 2, 6708 WB, Wageningen, the Netherlands
}

\begin{abstract}
Dioxins are environmental pollutants, potentially present in milk products, which have negative consequences for human health and for the firms and farms involved in the dairy chain. Dioxin monitoring in feed and food has been implemented to detect their presence and estimate their levels in food chains. However, the costs and effectiveness of such programs have not been evaluated. In this study, the costs and effectiveness of bulk milk dioxin monitoring in milk trucks were estimated to optimize the sampling and pooling monitoring strategies aimed at detecting at least 1 contaminated dairy farm out of 20,000 at a target dioxin concentration level. Incidents of different proportions, in terms of the number of contaminated farms, and concentrations were simulated. A combined testing strategy, consisting of screening and confirmatory methods, was assumed as well as testing of pooled samples. Two optimization models were built using linear programming. The first model aimed to minimize monitoring costs subject to a minimum required effectiveness of finding an incident, whereas the second model aimed to maximize the effectiveness for a given monitoring budget. Our results show that a high level of effectiveness is possible, but at high costs. Given specific assumptions, monitoring with $95 \%$ effectiveness to detect an incident of 1 contaminated farm at a dioxin concentration of $2 \mathrm{pg}$ of toxic equivalents/g of fat [European Commission's (EC) action level] costs $€ 2.6$ million per month. At the same level of effectiveness, a $73 \%$ cost reduction is possible when aiming to detect an incident where 2 farms are contaminated at a dioxin concentration of $3 \mathrm{pg}$ of toxic equivalents/g of fat (EC maximum level). With a fixed budget of $€ 40,000$ per month, the probability of detecting an incident with a single contaminated farm at a dioxin concentration equal to the $\mathrm{EC}$ action level is $4.4 \%$. This probability almost doubled $(8.0 \%)$ when aiming to detect the same incident but with a dioxin
\end{abstract}

Received July 3, 2012.

Accepted February 21, 2013.

${ }^{1}$ Corresponding author: victorhugo.lascanoalcoser@wur.nl concentration equal to the EC maximum level. This study shows that the effectiveness of finding an incident depends not only on the ratio at which, for testing, collected truck samples are mixed into a pooled sample (aiming at detecting certain concentration), but also the number of collected truck samples. In conclusion, the optimal cost-effective monitoring depends on the number of contaminated farms and the concentration aimed at detection. The models and study results offer quantitative support to risk managers of food industries and food safety authorities.

Key words: dioxin monitoring, dairy, linear programming, cost-effectiveness analysis

\section{INTRODUCTION}

Polychlorinated dibenzo-p-dioxins and polychlorinated dibenzofurans are known as dioxins. Polychlorinated biphenyls with dioxin-like properties are known as dioxin-like PCB (dl-PCB). Dioxins and dl-PCB are persistent organic pollutants (WHO, 2007) that belong to the 12 more prominent environmental contaminants as classified by the Stockholm Convention on Persistent Organic Pollutants (WHO, 2007; UNEP, 2009). Dioxins and dl-PCB are a potential threat to human health because of their toxicity at very low levels, their stability in the environment (WHO, 2007), and their bioaccumulation and biomagnification along food chains (Huwe, 2002; Schmid et al., 2002). If elevated levels are detected in food, dioxins may lead to extensive financial losses for food and feed businesses due to mitigation strategies and reduced sales (Velthuis et al., 2009; Lascano Alcoser et al., 2011).

In the EU, the intake of dioxins and dl-PCB by the consumers may still exceed the exposure limit of 14 $\mathrm{pg}$ of toxic equivalents (TEQ) $/ \mathrm{kg}$ of BW per week (De Mul et al., 2008). Prior studies have shown that foods of animal origin, mainly those containing fat, are the main contributors of dioxins in the human diet (Huwe, 2002). Studies have also shown that the main source of dioxins in food is contaminated feed (Buchert et al., 2001; Huwe, 2002) and feed ingredients (Huwe and Smith, 2005). In this regard, and due to the occurrence of several dioxin-food safety incidents in the 
last part of the 1990s (Malisch, 2000; Bernard et al., 2002), the EU established legislation for dioxins and dl-PCB in food and feed (EC, 2000; SCF, 2001). This legislation includes a strategy to reduce exposure levels over time (EC, 2001a) and defines maximum levels for these contaminants in food and feed products (EC, 2001b, c, 2006c). As part of this strategy, feed and food monitoring is conducted across the EU with the aim of diminishing exposure levels in the population (EC, 2001a, 2006a; EFSA, 2010).

Routine monitoring is a way to determine background levels and trends of dioxins in food and feed products (EC, 2001a) and to detect contaminated food and new sources in agri-food chains (EC, 2002, 2004; Heres et al., 2010; Hoogenboom et al., 2010). In spite of these apparent benefits, it is costly and complex to establish a dioxin monitoring plan (Buchert et al., 2001). One of the major difficulties is the lack of inexpensive and simple tests for real-time detection of dioxins (Kan and Meijer, 2007). This restricts the number of samples that can be analyzed (Huwe, 2002) and thereby reduces the capacity of monitoring to detect possible incidents. An improvement was the introduction of bioassays, such as Calux (Hiyoshi Corp., Shiga, Japan), but even these tests still run at relatively high costs and require several days.

Milk is one of the main contributors of dioxins and dl-PCB to the total exposure in the European population (EFSA, 2010). Consequently, milk dioxin incidents may have a potential salient effect to human health. Additionally, the dairy chains in different countries have been one of the food chains repeatedly involved in dioxin incidents (e.g., Belgian crisis in 1999, Dutch incident in 2004), with salient potential financial effect to the involved farms and firms along the chain (Lascano Alcoser et al., 2011). In this study, the cost and effectiveness of bulk milk dioxin monitoring at milk trucks were estimated with the objective of optimizing the sampling and pooling monitoring strategies aiming at detecting a dioxin incident. This study elicits valuable information to risk managers about the relation between the financial resources spent on monitoring dioxins and the capacity of this system to detect a contamination.

\section{MATERIALS AND METHODS}

Two optimization models were built using linear programming (Dijkhuizen and Morris, 1997). The first model (MC) aimed to minimize the monitoring costs subject to a minimum required effectiveness, whereas the second model (ME) aimed to maximize the effectiveness of monitoring for a given budget for monitoring. The models evaluated a bulk milk dioxin monitoring plan in milk trucks covering 20,000 dairy farms located in an area of $40,000 \mathrm{~km}^{2}$. Milk trucks, which transport milk from the dairy farms to the milk processing plants, were randomly selected at each sampling time. Within this framework, a dioxin incident is assumed to last for at least $1 \mathrm{mo}$, which is realistic considering the turnover of feed and the slow elimination of these compounds in dairy cows (Hoogenboom et al., 2010). The models were applied to 8 preselected contamination scenarios representing dioxin incidents of different sizes to be detected (called detectable incidents). The size of a detectable incident was determined by the combination of the number of expected contaminated farms (1 or 10) and the target dioxin concentration $(2,3,10$, or 20 pg of TEQ/g of fat) in the tank milk of contaminated farms (Table 1).

The bulk milk dioxin monitoring aimed to detect at least one of the contaminated farms with a concentration $\left(c_{c f}\right)$ equal or higher than the action level for dioxins. The action level $\left(c_{A L}\right)$ was defined as the concentration of dioxins at which authorities and food business operators can decide to identify the source of

Table 1. Description of the contamination scenarios

\begin{tabular}{|c|c|c|}
\hline \multirow[b]{2}{*}{$\begin{array}{l}\text { Scenario } \\
\text { code }\end{array}$} & \multicolumn{2}{|c|}{ Size of detectable incident } \\
\hline & $\begin{array}{c}\text { No. of expected } \\
\text { contaminated farms }(\mathrm{F})\end{array}$ & $\begin{array}{l}\text { Target concentration } \\
\text { (i.e., dioxin concentration at farms })^{1}(\mathrm{C})\end{array}$ \\
\hline $\mathrm{F} 1-\mathrm{C} 2$ & 1 & $2 \mathrm{pg}$ of $\mathrm{TEQ} / \mathrm{g}$ of $\mathrm{fat}^{2}$ \\
\hline F1-C3 & 1 & $3 \mathrm{pg}$ of TEQ/g of $\mathrm{fat}^{3}$ \\
\hline F1-C10 & 1 & $10 \mathrm{pg}$ of $\mathrm{TEQ} / \mathrm{g}$ of fat \\
\hline $\mathrm{F} 1-\mathrm{C} 20$ & 1 & $20 \mathrm{pg}$ of TEQ/g of fat \\
\hline $\mathrm{F} 10-\mathrm{C} 2$ & 10 & $2 \mathrm{pg}$ of TEQ $/ \mathrm{g}$ of $\mathrm{fat}^{2}$ \\
\hline F10-C3 & 10 & $3 \mathrm{pg}$ of $\mathrm{TEQ} / \mathrm{g}$ of $\mathrm{fat}^{3}$ \\
\hline F10-C10 & 10 & $10 \mathrm{pg}$ of TEQ $/ \mathrm{g}$ of fat \\
\hline $\mathrm{F} 10-\mathrm{C} 20$ & 10 & $20 \mathrm{pg}$ of TEQ/g of fat \\
\hline
\end{tabular}


the contamination (EC, 2001c). The European Commission (EC) action level for dioxins in raw milk at dairy farms equaled $2 \mathrm{pg}$ of World Health Organization TEQ/g of fat (EC, 2006a). To simplify the model, and because no legal EC action level exists for the sum of dioxins and dl-PCB, only dioxins were assumed to be the cause of the incident (not dl-PCB).

The assumed sampling and pooling procedures are presented in Figure 1. In this regard, milk trucks collect milk from several different farms. Randomly, milk trucks are sampled by a worker of the dairy company or the truck driver just before the milk is pumped into the silos of the milk processing plants. The collected truck samples are transported to a laboratory where they are mixed into pooled samples. These pooled samples are tested for dioxins. Collected truck samples are stored at the laboratory for further analysis in case an incident is detected after testing the pooled samples. Each pooled sample is tested using a screening method, such as the Calux bioassay (EC, 2006b), to determine the possible presence of dioxins above the target level for a single farm's tank milk. Any pooled sample with an estimated concentration of dioxins equal or above a certain decision limit is considered suspect. This decision limit represents the highest concentration of dioxins above the background level below which a sample is considered not to be contaminated (tested negative for dioxins). The decision limit is estimated considering the variability of the test results (explained in detail later). The background level is the measured concentration of dioxins in milk samples due to the ubiquitous condition of dioxins as an environmental pollutant. In this study, it is assumed that noncontaminated milk samples contain a dioxin concentration equal to the assumed background level for each type of sample. Suspected pooled samples are analyzed with the highresolution gas chromatography/high-resolution mass spectrometry (HRGC/HRMS) to verify the presence and concentration of dioxins above the decision limit for HRGC/HRMS, which is the only official confirmatory method (EC, 2006b). In case a pooled sample is confirmed to be positive for dioxins, all truck samples originally mixed into the contaminated pooled sample are tested individually using the screening method and, if suspected, the confirmatory method. Once a contaminated truck sample is identified, all farms from which the milk was collected by the truck are sampled again and tested with the screening method, and with the confirmatory method if suspected. In this way, the contaminated farm(s) and potentially the source of the contamination can be determined (Figure 2). Testing samples with only the screening method could lead to false-positive contaminations; therefore, a confirmation is required. As the confirmatory method is more expensive than the screening method, the confirmatory method is only used to test the suspected contaminated samples.

\section{Optimization Models}

Two optimization models were built with the aim of optimizing the sampling and pooling strategies of milk dioxin monitoring in milk trucks. Each optimization model consisted of an objective function, a set of constraints, and the optimized variables. The objective of the optimization models was either to minimize the monitoring costs [TMC $\left.\left(n s_{t}, n s_{\text {truck-mix }}\right)\right]$ or to maximize the effectiveness function [Prob $D_{c f}\left(n s_{t}\right.$, $\left.\left.n s_{\text {truck-mix }}\right)\right]$ when applying the MC or the ME model, respectively. The minimum required effectiveness $(E)$ and the available budget for monitoring $(B)$ were the main constraints of the MC and ME model, respectively. The optimized variables were the number of milk trucks to be sampled, named collected truck samples $\left(n s_{t}\right)$ and the ratio at which, for testing and aiming to detect certain concentration, collected truck samples are mixed into a pooled sample, named truck samples mixed $\left(n s_{\text {truck-mix }}\right)$. Both variables were included in the cost function as well as the effectiveness function, which are explained in detail later. The cost and effectiveness functions were created in Microsoft Excel 2010 (Redmond, WA). Additionally, the optimization models were simulated using the Solver command from Frontline Systems Inc. (Frontline Systems Inc., 2011), part of the What If Tools of Microsoft Excel 2010.

The MC model is written as follows

$$
\text { Minimize: } T M C\left(n s_{t}, n s_{\text {truck-mix }}\right) \text {, }
$$

Subject to: Prob $D_{c f}\left(n s_{t}, n s_{\text {truck-mix }}\right) \geq E, 0 \leq n s_{t} \leq N s_{t}$,

$$
1 \leq n s_{\text {truck-mix }} \leq N s_{\text {truck-mix }}
$$

where $N s_{t}$ is the maximum number of collected truck samples that can be taken per month; and $N s_{\text {truck-mix }}$ is the maximum number of truck samples that can be mixed into one pooled sample. The minimal $E$ were assumed to be $95.0 \%$, which can be adjusted by the food safety decision makers.

The ME model is written as follows

$$
\text { Maximize: Prob } D_{c f}\left(n s_{t}, n s_{\text {truck-mix }}\right) \text {, }
$$

Subject to: $T M C\left(n s_{t}, n s_{\text {truck-mix }}\right) \leq B, 0 \leq n s_{t} \leq N s_{t}$,

$$
1 \leq n s_{\text {truck-mix }} \leq N s_{\text {truck-mix }} \text {. }
$$




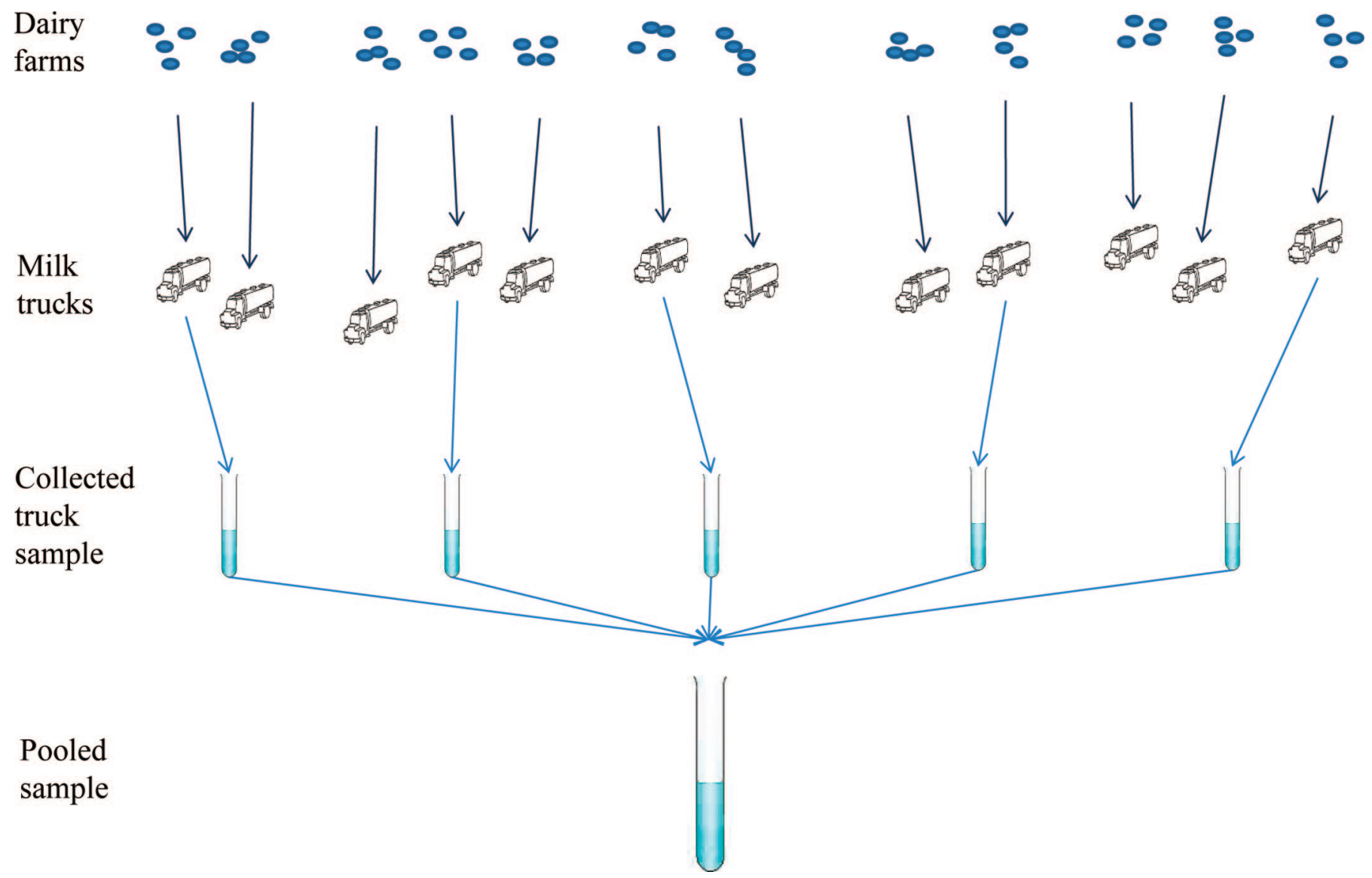

Figure 1. Example of a sampling scheme where milk trucks containing milk from 4 dairy farms are sampled; these samples are then mixed into a pooled sample. Color version available in the online PDF.

The monitoring budget $(€ 40,000)$ was selected given the results obtained when running the MC model so as to obtain comparable results when discussing the outcomes of both models. Note that the monitoring budget did not include additional costs for determining the source of the contamination once a positive pooled sample is detected (so called incident costs). A detailed description of the incident costs is given in the next section.

\section{Costs Function of the Milk Dioxin Monitoring}

The $T M C$ includes monitoring costs $(M C)$ and incident costs $(I C)$, calculated by

$$
T M C=M C+I C,
$$

where $M C$ includes all activities performed to measure the concentration of dioxins in pooled samples, which equals the first row of Figure 2. Monitoring costs are the sum of sampling $(M S C)$ and testing $(M T C)$ costs, calcutated by

$$
M C=M S C+M T C .
$$

Sampling costs at monitoring are given by

$$
M S C=(l c+m c+t c s+s c) \times n s_{t},
$$

where $l c$ is the labor cost for personnel who take the samples; $m c$ is the materials cost for all equipment and tools used to take samples; tcs is the cost of transporting the samples to the laboratory; and $s c$ is the cost of storing the samples to allow further analysis.

The sum of testing costs $(M T C)$ are given by

$$
\begin{aligned}
& M T C=\left[\left(\text { test }_{\text {scree }}+l c_{\text {test }}\right) \times \frac{n s_{t}}{n s_{\text {truck-mix }}}\right]+ \\
& {\left[\left(\text { test }_{\text {conf }}+l c_{\text {test }}\right) \times \% p s_{\text {scree }} \times \frac{n s_{t}}{n s_{\text {truck-mix }}}\right],}
\end{aligned}
$$

where test $t_{\text {scree }}$ and test $t_{\text {conf }}$ are the costs of the screening and confirmatory methods, respectively; $l c_{\text {test }}$ is the sum of the labor costs for registering and evaluating the 


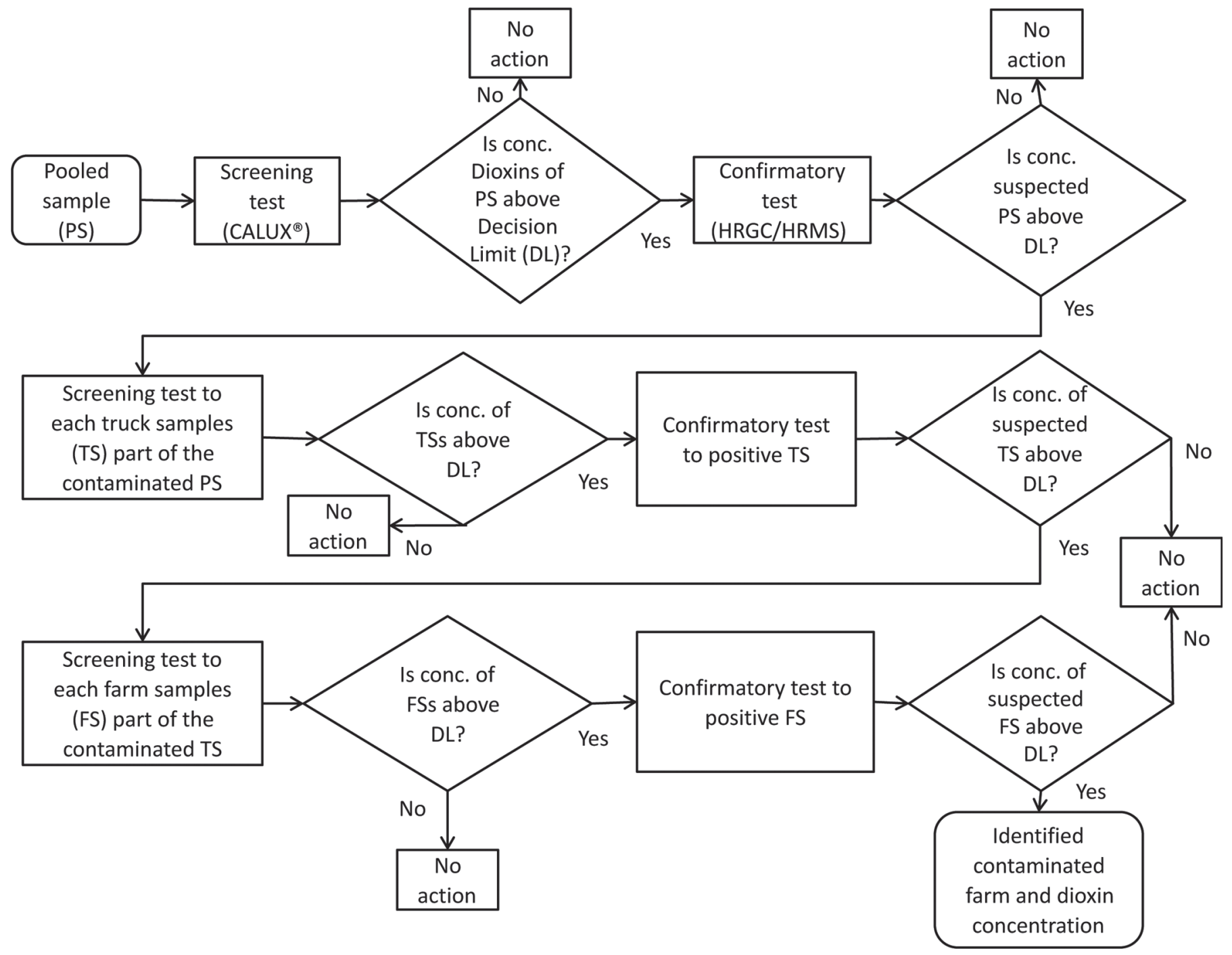

Figure 2. Decision process for testing dioxins in pooled samples, truck samples, and farm samples with a screening test, such as Calux (Hiyoshi Corp., Shiga, Japan), and confirmatory test high-resolution gas chromatography/high-resolution mass spectrometry (HRGC/HRMS). Decision limits (DL) will vary for each step, depending on whether farm, truck, or pooled samples are tested.

test results (i.e., $\left.l c_{\text {test }}=l c_{\text {test-reg }}+l c_{\text {test-eva }}\right) ;$ and $\% p s_{\text {scree }}$ is the proportion of the total number of pooled samples that are tested positive by the screening test.

Incident costs $(I C)$ includes costs related to tracing the source and concentration of dioxins at the level of truck samples and the farm samples that correspond to the second and third row of Figure 2, respectively:

$$
I C=I S C+I T C,
$$

where $I S C$ is the cost of sampling milk from the farms that are suspected to be the source of the incident (after testing individual truck samples); and ITC is sum of the costs of individually testing each truck sample contained in the contaminated pooled sample, and each farm sample from those farms that are suspected to be the source of the incident.

The cost of sampling milk from suspect farms (ISC) is given by Equation 5, where $n s_{t}$ is the number of farm samples that should be collected from farms suspected to be contaminated $\left(n s_{f}\right)$. That is given by

$$
n s_{f}=n s_{\text {truck }-c} \times n s_{\text {farm }- \text { mix }},
$$

where $n s_{\text {truck-c }}$ is the number of truck samples with a higher dioxin concentration than the decision limit; and $n s_{\text {farm-mix }}$ is the number of farms served by 1 milk truck (fixed at 4).

The sum of the costs of individually testing each truck sample $(I T C)$ is given by 


$$
\begin{gathered}
I T C=\left[\left(\text { test }_{\text {scree }}+l c_{\text {test }}\right) \times n s_{\text {truck-pool }}\right]+\left[\left(\text { test }_{\text {conf }}\right.\right. \\
\left.\left.+l c_{\text {test }}\right) \times n s_{\text {truck-suspec }}\right]+\left[\left(t e s t_{\text {scree }}+l c_{\text {test }}\right) \times n s_{f}\right] \\
+\left[\left(t e s t_{\text {conf }}+l c_{\text {test }}\right) \times n s_{\text {farm-conf }}\right],
\end{gathered}
$$

where $n s_{\text {truck-pool }}$ is the number of collected truck samples mixed into the positive pooled sample which varies with the simulated $n s_{\text {truck-mix }} ; n s_{\text {truck-suspec }}$ is the number of collected truck samples mixed into the positive pooled sample identified from the simulated $n s_{\text {truck-mix }}$ and having an estimated dioxin concentration higher than the decision limit; and $n s_{\text {truck-conf }}$ is the number of farm samples that have a higher dioxin concentration than the decision limit. It is assumed that only 1 pooled sample and, subsequently, 1 collected truck sample and 1 farm sample test positive. All inputs variables for monitoring cost function are given in Table 2 .

\section{Effectiveness Function of Milk Dioxin Monitoring}

The effectiveness of bulk milk dioxin monitoring from milk trucks is defined in this study as the probability of detecting at least 1 contaminated farm (Prob $D_{c f}$ ) per month at a target concentration (e.g., 1 of 10 contaminated farms out of 20,000 with a dioxin concentration of $2 \mathrm{pg}$ of TEQ/g of fat).

The Prob $\left(D_{c f}\right)$ follows a binomial distribution

$$
\operatorname{Prob}\left(D_{c f}\right)=1-\operatorname{Prob}\left(N D_{c f}\right),
$$

where Prob $\left(N D_{c f}\right)$ is the probability of not detecting a contaminated farm (i.e., the number of detections equals zero; $x=0)$ :

$$
\begin{aligned}
& P\left(N D_{c f}\right)=\left(\begin{array}{l}
n s_{t} \\
x
\end{array}\right) \times\left[\operatorname{Prob}\left(D_{c t}\right) \times \operatorname{Prob}\left(t_{p o s}\right)\right]^{x} \\
& \times\left\{1-\left[\operatorname{Prob}\left(D_{c t}\right) \times \operatorname{Prob}\left(t_{p o s}\right)\right]\right]^{n s_{t}-x},
\end{aligned}
$$

where Prob $\left(D_{c t}\right)$ is the probability of sampling at least 1 contaminated milk truck; and Prob $\left(t_{p o s}\right)$ is the probability that a true contaminated truck sample is tested positive.

The Prob $\left(D_{c t}\right)$ is the number of contaminated trucks in the defined period $t$ (one month of $30.4 \mathrm{~d} ; n_{c t \_t}$ ) divided by the total number of trucks collecting milk in that period $\left(N_{t \_t}\right)$ :

$$
\operatorname{Prob}\left(D_{c t}\right)=\frac{n_{c t_{-} t}}{N_{t_{-} t}}
$$

where $n_{\text {ct_t }}$ equals the number of contaminated farms $\left(n_{c f_{-} t}\right)$ in period $t$ multiplied by the number of days in

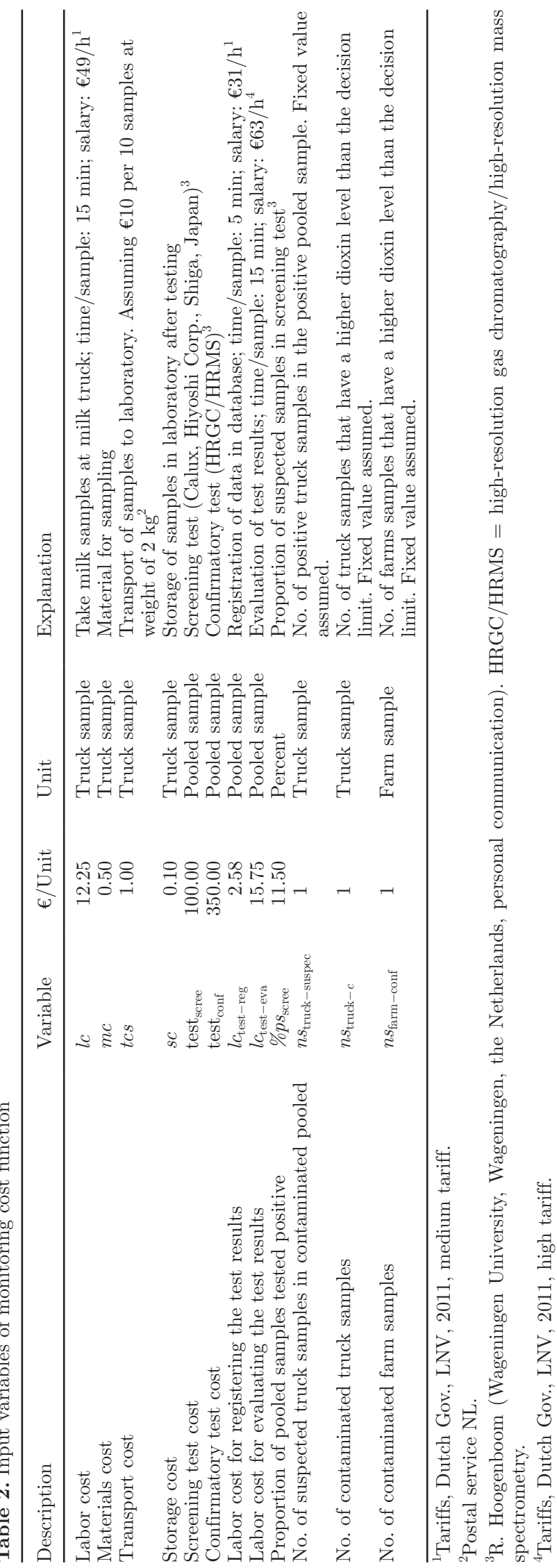


$t$ divided by the number of days between 2 subsequent deliveries $\left(f_{m d}\right)$ :

$$
n_{c t_{-} t}=n_{c f_{-} t} \times \frac{t}{f_{m d}} .
$$

The total number of trucks collecting milk in period $t\left(N_{t \_t}\right)$ equals the maximum number of truck samples that can be collected per month $\left(N s_{t}\right)$, which is given by

$$
N_{t_{-} t}=\frac{N_{d f} \times t}{f_{m d} \times n_{\text {farm-mix }}},
$$

where $\mathrm{N}_{d f}$ is the total number of dairy farms delivering milk to the dairy processors.

The Prob $\left(\operatorname{tpos}_{c t}\right)$ is the probability that the concentration of the tested pooled sample is higher than the decision limit $\left(c_{c p}>c_{D L}\right)$ given that milk from at least 1 farm tank has a higher concentration of dioxins than the action level $\left(c_{c f}>c_{A L}\right)$. This probability equals the sensitivity of the analytical methods ( test $_{\text {sensitivity }}$ ), which is assumed to be equal for both the screening and confirmatory test.

The concentration of dioxins in the contaminated pooled sample $\left(c_{c p}\right)$ depends on the dilution of the initial dioxin concentration due to the mixing of milk from different dairy farms by the truck collector and when preparing a pooled sample. In this study, it is assumed that 1 of the 4 farms collected in 1 truck is contaminated. In practice, milk from more than 1 farm contained in the truck sample could be contaminated.

The first dilution effect depends on the proportion of milk delivered by the contaminated farm relative to the total milk transported by the truck collector and the $c_{c f}$. Thus, the dioxin concentration of the contaminated truck sample $\left(c_{c t}\right)$ is given by

$$
c_{c t}=\left[\frac{\Sigma_{i}\left(c_{n c f_{i}} \times \% \text { fat } \times \mathrm{qmilk}_{n c f_{i}}\right)+c_{c f} \times \% \text { fat } \times \mathrm{qmilk}_{c f}}{\% \text { fat } \times \mathrm{Qmilk}_{c t}}\right],
$$

where $c_{n c f_{i}}$ is the concentration of dioxins at a noncontaminated farm $(i)$; qmilk ncfi $_{i}$ is the amount of milk delivered by the noncontaminated farm $(i)$; \%fat is the proportion of fat in the milk (given that dioxins are present in the milk fat portion); qmilk $\mathrm{k}_{c f}$ is the amount of milk delivered by the contaminated farm; and Qmilk ${ }_{c t}$ is the total amount of milk transported by the contaminated milk truck. For simplification, it is assumed that all farms deliver the same amount of milk with the same proportion of fat and that the milk truck is full. Equation (15) can then be simplified as follows,

$$
c_{c t}=\frac{\left[\Sigma_{i}\left(c_{n c f_{i}}\right)+c_{c f}\right]}{n_{\text {farm-mix }}} .
$$

The second dilution effect varies with the proportion of the contaminated collected truck sample mixed into a pooled sample. The dioxin concentration of the contaminated pooled sample $\left(c_{c p}\right)$ is quantified as follows

$$
c_{c p}=\frac{c_{c t}+\left(c_{n c t} \times n s_{\text {truck }-n c}\right)}{\left(n s_{\text {truck }-n c}+n s_{\text {truck }-c}\right)},
$$

where $c_{n c t}$ is the average dioxin concentration of the noncontaminated collected truck samples (assumed to be equal to the background level for truck samples); $n s_{\text {truck }-n c}$ are the number of noncontaminated truck samples combined into a pooled sample. Assuming that only 1 collected truck sample is expected to be contaminated $\left(n s_{\text {truck }-c}=1\right)$, equation (16) is rearranged as follows:

$$
c_{c p}=\frac{c_{c t}+\left(c_{n c t} \times n s_{\text {truck }-n c}\right)}{\left(n s_{\text {truck }-n c}+1\right)} .
$$

Given that the probability of a contaminated pooled sample testing positive depends on $c_{c p}>c_{D L}$, the following holds,

$$
\frac{c_{c t}+\left(c_{n c t} \times n s_{\text {truck }-n c}\right)}{\left(n s_{\text {truck }-n c}+1\right)}>c_{D L} .
$$

Consequently, to allow detection, a maximum number of noncontaminated collected truck samples $\left(N s_{\text {truck-nc }}\right)$ combined into a pooled sample exists. Thus, rearranging equation 19 gives

$$
N s_{\text {truck }-n c}<\frac{c_{c t}-c_{D L}}{c_{D L}-c_{n c t}},
$$

where $c_{D L}$ is the dioxin concentration at the decision limit for pooled samples, which is set as follows:

$$
c_{D L}=c_{n c p}+\left(c_{n c p} \times p v_{n c p}\right),
$$

where $c_{n c p}$ is the dioxin concentration of noncontaminated pooled samples (background level for pooled samples); and $p v_{n c p}$ is the assumed percentage of possible positive deviation of the background level from its mean value with respect to the variability in concentration of collected truck samples. Assuming 1 positive collected truck sample in a pooled sample, $N s_{\text {truck-mix }}$ is given by: 


$$
N s_{\text {truck-mix }}=N s_{\text {truck-nc }}+1 .
$$

All input variables for the monitoring effectiveness function are given in Table 3.

\section{RESULTS}

Dioxin monitoring aimed to detect at least 1 contaminated dairy farm out of 20,000 at a certain target dioxin concentration in incidents with different contamination scenarios. These scenarios varied depending on the size of the detectable incident. It was assumed that milk samples were collected from milk trucks randomly selected at each sampling time. These truck samples may be combined into pooled samples to increase the number of farms tested. The pooled samples were subsequently tested by a screening method and, if exceeding the decision limit, by the confirmatory method. Prices of the tests were set at $€ 100$ and $€ 350$, based on the high efficiency of the screening method due to the large sample volumes. The costs and effectiveness of the monitoring plan were minimized (given a minimum required effectiveness) or maximized (given a certain maximum budget) when applying the MC or the ME model, respectively. The optimized variables were the number of milk trucks to be sampled (collected truck samples) and the ratio at which, for testing and aiming to detect certain concentration, collected truck samples are mixed into a pooled sample (truck sample mixed).

\section{Optimization Results for the 95\% Effectiveness Level}

The MC optimization results for a minimal effectiveness of $95 \%$ and for the 8 contamination scenarios are shown in Table 4 . The optimal number of collected truck samples and the number of truck samples mixed varies with the number of expected contaminated farms and the concentration of dioxins at farm level, respectively. The bigger the detectable incident was, the lower the monitoring costs required to detect the contamination.

A 10-fold increase in the number of contaminated farms reduces the number of collected truck samples required to detect the contamination from 15,283 to 1,527 samples (Table 4). This decrease in the number of collected truck samples leads to a $90 \%$ reduction in the sampling costs at monitoring. However, the marginal reduction decreases with each additional expected contaminated farm (Figure 3). A reduction of $80 \%$ in the sampling costs is obtained when the number of expected contaminated farms increases from 1 to 5 .

An increase in the target concentration of dioxins at the contaminated farm(s) enables mixing of more truck samples into a pooled sample. The higher the

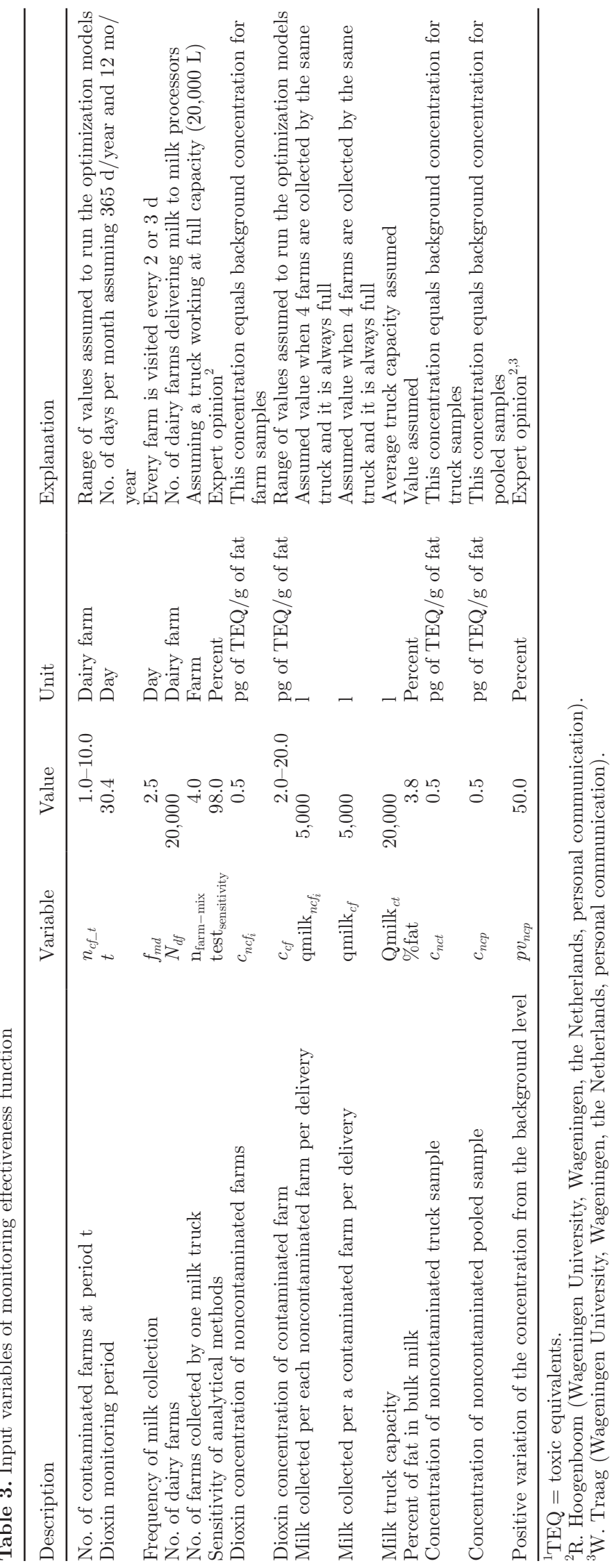


Table 4. Optimal number of samples for 8 contamination scenarios

\begin{tabular}{lcccc}
\hline Scenario & $\begin{array}{c}\text { No. of collected } \\
\text { truck samples } \\
\text { per month }\end{array}$ & $\begin{array}{c}\text { No. of truck samples } \\
\text { mixed into a } \\
\text { pooled sample }\end{array}$ & $\begin{array}{c}\text { No. of pooled } \\
\text { samples tested } \\
\text { per month }\end{array}$ & $\begin{array}{c}\text { Monitoring costs } \\
\text { per month } \\
\text { (€, in thousands) }\end{array}$ \\
\hline F1-C2 & 15,283 & 1 & 15,283 & 2,667 \\
F1-C3 & 15,283 & 2 & 7,642 & 1,439 \\
F1-C10 & 15,283 & 9 & 1,698 & 484 \\
F1-C20 & 15,283 & 19 & 804 & 340 \\
F10-C2 & 1,527 & 1 & 1,527 & 266 \\
F10-C3 & 1,527 & 2 & 764 & 43 \\
F10-C10 & 1,527 & 9 & 169 & 34 \\
F10-C20 & 1,527 & 19 & 80 & 38 \\
\hline
\end{tabular}

mixing ratio, the smaller the number of pooled samples tested, and consequently, the lower the testing cost per collected truck sample (Table 4 and Figure 4). The optimal number of truck samples mixed into a pooled sample increases linearly from 1 to 19 at a constant rate of 1 truck sample for each additional unit of dioxin concentration (Figure 4). However, the marginal reduction in the testing costs per collected truck sample decreases for each additional unit of the target concentration. For example, the testing costs per collected truck sample decreases by $€ 80$ when the target concentration was increased from 2 to $3 \mathrm{pg}$ of TEQ/g of fat, and by $€ 0.50$ when the target concentration was increased from 19 to $20 \mathrm{pg}$ of TEQ/g of fat. The largest reduction of testing costs given by an increasing number of truck samples mixed into a pooled sample is observed when the target concentration increases from 2 to $6 \mathrm{pg}$ of TEQ/g of fat (Figure 4). Note that at the target dioxin concentration of $2 \mathrm{pg}$ of TEQ/g of fat, the collected truck samples need to be tested individually because pooling would dilute the concentration of dioxins below the decision limit.

When increasing the number of contaminated farms and the target dioxin concentration simultaneously (i.e., a bigger detectable incident), the results show that monitoring costs decrease markedly (Table 5). Monitoring costs differ widely between scenarios. They vary from $€ 2.6$ million when aiming to detect at least 1 contaminated farm at action level $(2 \mathrm{pg}$ of TEQ/g of fat; reference scenario) to €34,063 when aiming to detect at least 1 of 10 contaminated farms at $20 \mathrm{pg}$ of TEQ/g of fat (Table 5). This represents a reduction in monitoring costs of approximately $98 \%$. However, a significant cost reduction of $73 \%$ can already be obtained when aiming to detect at least 1 of 2 contaminated farms at the maximum level ( $3 \mathrm{pg}$ of TEQ/g of fat).

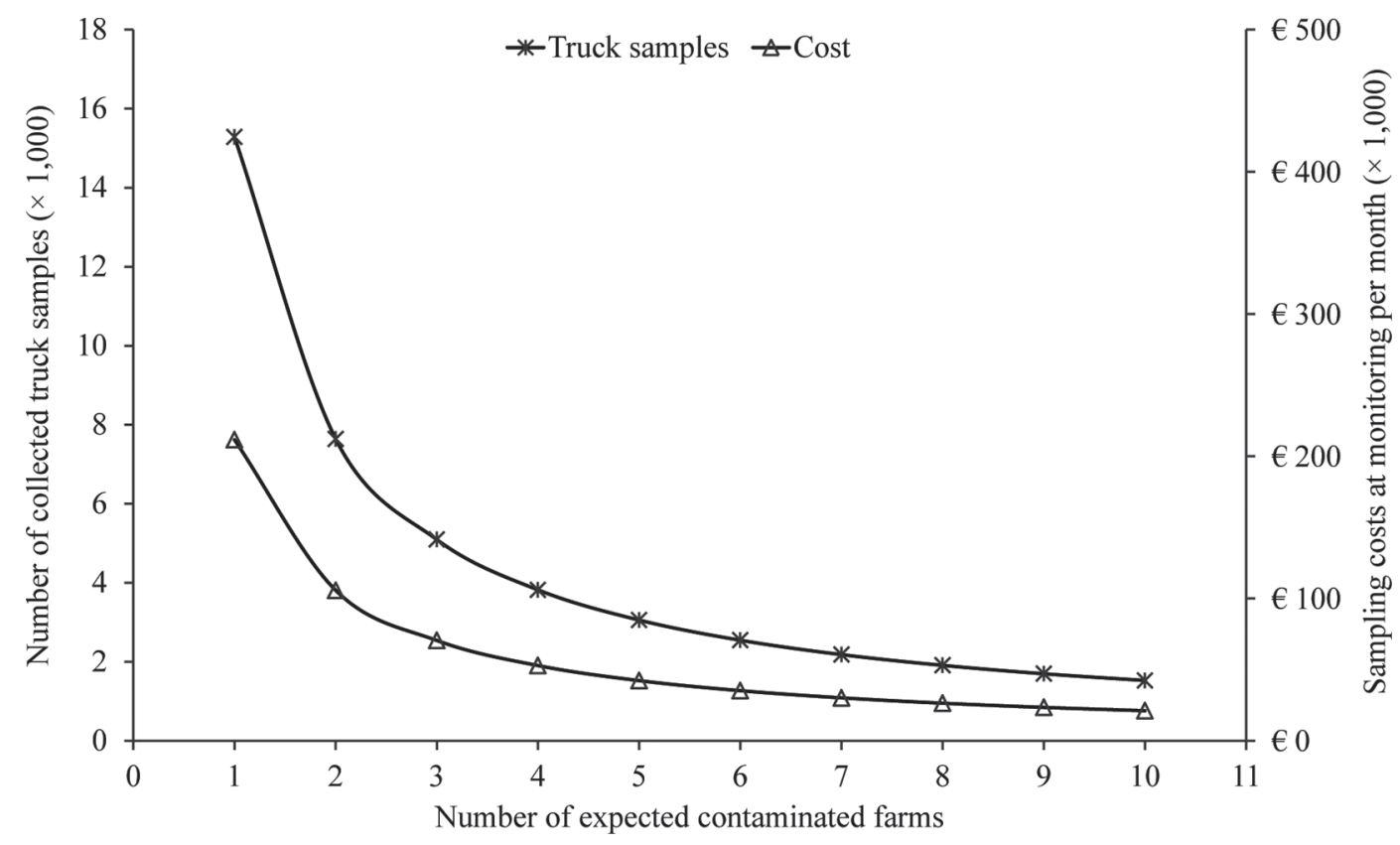

Figure 3. Effect of increasing the number of expected contaminated farms on the number of collected truck samples and the sampling monitoring costs. 


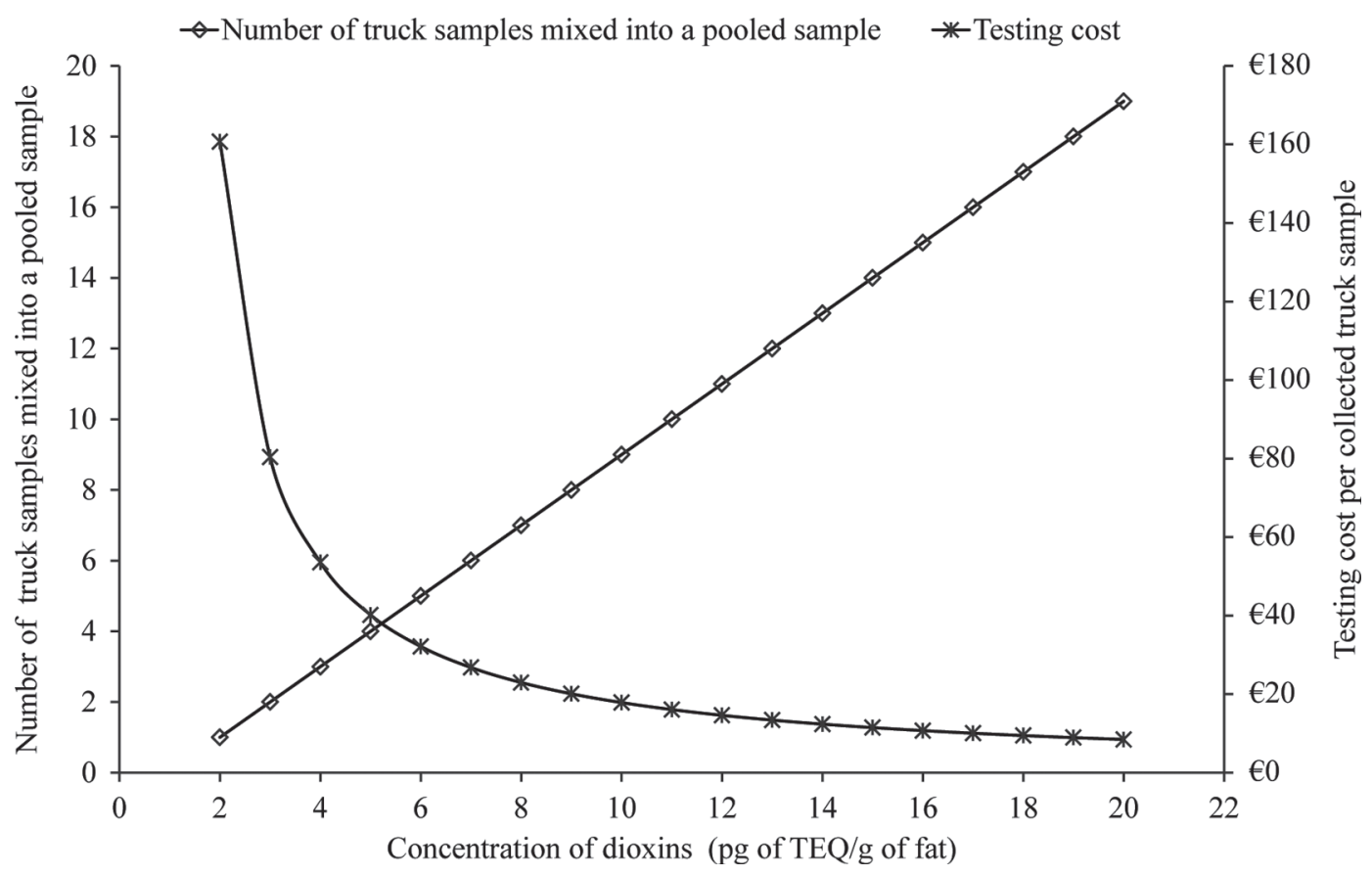

Figure 4. Effect of increasing the target concentration of dioxins on the optimal number of truck samples mixed into a pooled sample and the testing cost per collected truck sample. TEQ $=$ toxic equivalents.

\section{The Effect on the Monitoring Costs when Varying the Required Effectiveness Level}

Figure 5 shows the increase in monitoring costs seen as the required effectiveness level increased. As seen in Figure 5, for all effectiveness levels, monitoring costs are higher for incidents with a lower number of expected contaminated farms (F1-C2, F1-C10) than for incidents with a higher number of expected contaminated farms (F10-C2, F10-C10). Monitoring costs vary among scenarios with different targeted detectable incidents. The cost-effective curve moves upwards and become steeper when aiming to identify smaller detectable incidents. This implies that the cost of increasing the effectiveness at the same proportion and from the same initial level is higher as the size of the incident became smaller. The cost of increasing the effectiveness level from 80 to $85 \%$ varies from $€ 256,200$ at the smallest detectable incident to $€ 4,600$ when aiming to detect at least 1 of 10 contaminated farms at $10 \mathrm{pg}$ of TEQ/g of fat.

\section{ME Optimization Results for a Fixed Monthly Monitoring Budget}

The results of the ME optimization model for a fixed monthly monitoring budget of $€ 40,000$ for the 8 scenarios are presented in Table 6. At any budget, the bigger the detectable incident, the higher the effectiveness obtained. The optimal number of collected truck samples and the optimal number of collected truck samples mixed into a pooled sample are limited by the monitoring budget and the target dioxin concentration at the contaminated farm(s) tank milk.

An increase in the target dioxin concentration increased the number of collected truck samples that could be combined into a pooled sample, and thus the number of pooled samples that must be tested decreased (Table 6, C2 versus C3, C10 and C20). If fewer pooled samples are tested, the actual testing costs can be reduced and, therefore, the remaining budget can be allocated for sampling more milk trucks. The bigger the number of collected truck samples, the higher the effectiveness that can be obtained for the same budget. When focusing on a target concentration equivalent to the action level ( $2 \mathrm{pg}$ of TEQ/g of fat) at just one farm, the maximum effectiveness obtained is $4.4 \%$. The effectiveness level almost doubles (8.0\%) after increasing the target dioxin concentration from the action to the maximum level (3 pg of TEQ/g of fat). At the second scenario, 2 collected truck samples can be pooled and, therefore, fewer pooled samples must be tested, allowing sampling of more collected truck samples and increasing the probability of detecting the contamination. Effectiveness increases to 36.2 and $56.5 \%$ when looking for a contamination that affects 10 farms at the action and maximum levels, respectively.

An increase in the number of expected contaminated farms has no effect on the number of collected truck 


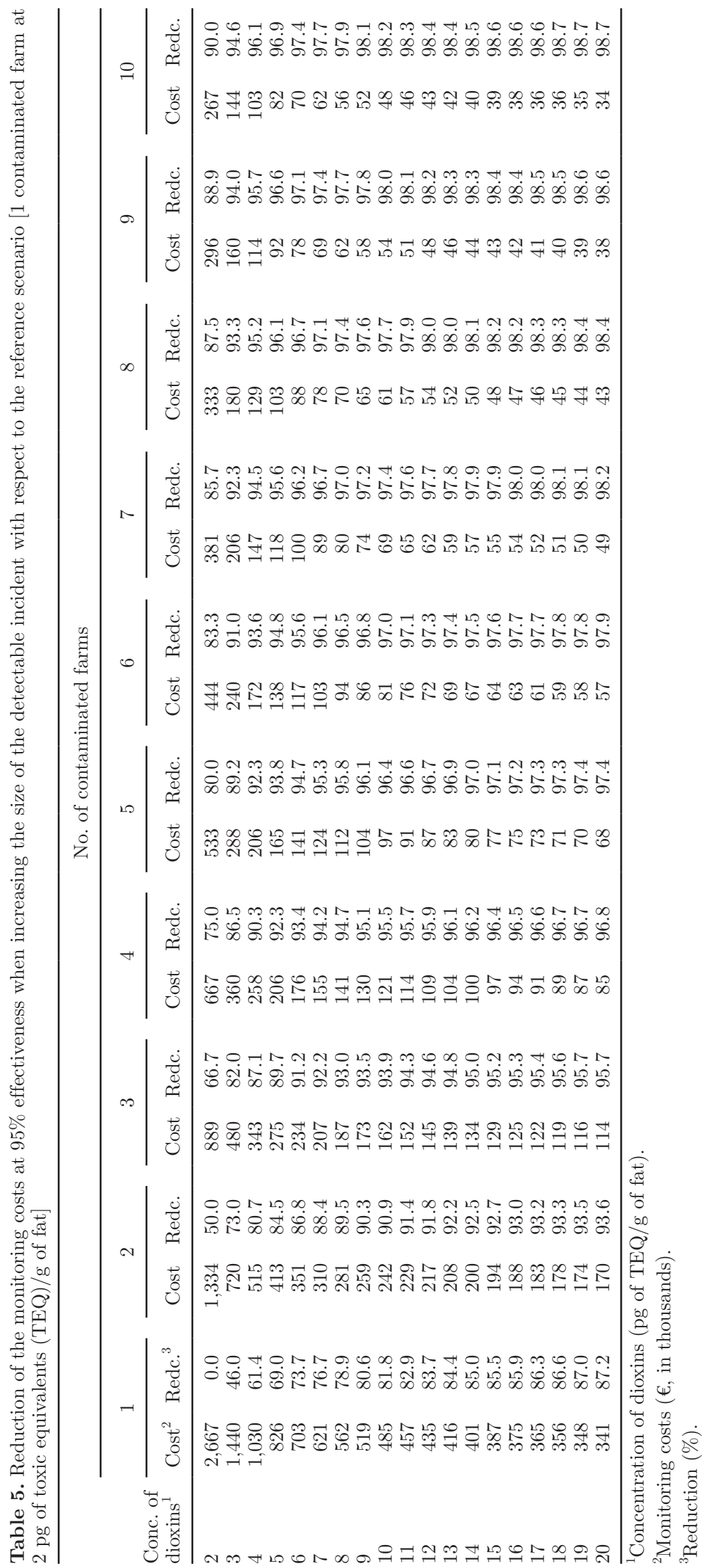


Table 6. Optimal number of samples for 8 contamination scenarios

\begin{tabular}{lcccc}
\hline Scenario & $\begin{array}{c}\text { No. of collected } \\
\text { truck samples } \\
\text { per month }\end{array}$ & $\begin{array}{c}\text { No. of truck samples } \\
\text { mixed into a } \\
\text { pooled sample }\end{array}$ & $\begin{array}{c}\text { No. of pooled } \\
\text { samples tested } \\
\text { per month }\end{array}$ & $\begin{array}{c}\text { Monitoring } \\
\text { effectiveness (\%) }\end{array}$ \\
\hline F1-C2 & 229 & 1 & 229 & 4.4 \\
F1-C3 & 425 & 2 & 212 & 8.0 \\
F1-C10 & 1,262 & 9 & 140 & 21.9 \\
F1-C20 & 1,793 & 19 & 94 & 36.6 \\
F10-C2 & 229 & 1 & 229 & 56.5 \\
F10-C3 & 425 & 2 & 212 & 91.6 \\
F10-C10 & 1,262 & 9 & 140 & 97.0 \\
F10-C20 & 1,793 & 19 & 94 & \\
\hline
\end{tabular}

samples or the mixing ratio at which truck samples are combined into a pooled sample (Table 6, F1 vs. F10). However, the effectiveness level increases with a higher number of contaminated farms. Increasing the number of expected contaminated farms from 1 to 10 combined with the lowest dioxin concentration $(2 \mathrm{pg}$ of TEQ/g of fat) increases the effectiveness from 4.4 to $36.2 \%$. A higher range of effectiveness is observed (from 29.6-97.0\%) in scenarios where the number of contaminated farms was increased and combined with the highest dioxin concentration (20 pg of TEQ/g of fat).

For each additional contaminated farm, the costeffectiveness curve moves upwards and become steeper, increasing the probability of detecting the contamination (Figure 6). However, the shape of the curve becomes much less steep for any concentration higher than $10 \mathrm{pg}$ of TEQ/g of fat. This implies that the mar- ginal increase in the effectiveness for each additional contaminated farm is lower for scenarios with target concentrations above $10 \mathrm{pg}$ of TEQ/g of fat than for those scenarios below this concentration (Figure 6).

\section{The Effect on the Effectiveness Level when Varying the Monitoring Budget}

Our results show that with a higher available budget a higher effectiveness level is obtained for all scenarios (Figure 7). However, when the monitoring budget is increased from $€ 10,000$ to $€ 50,000$, a steeper increase in effectiveness is obtained at scenarios with bigger detectable incidents (i.e., F10-C10). In such scenarios, the marginal increase in effectiveness for each additional euro invested in monitoring is bigger than for those scenarios representing small detectable incidents (i.e., F1-C2). Consequently, detecting at least one contami-

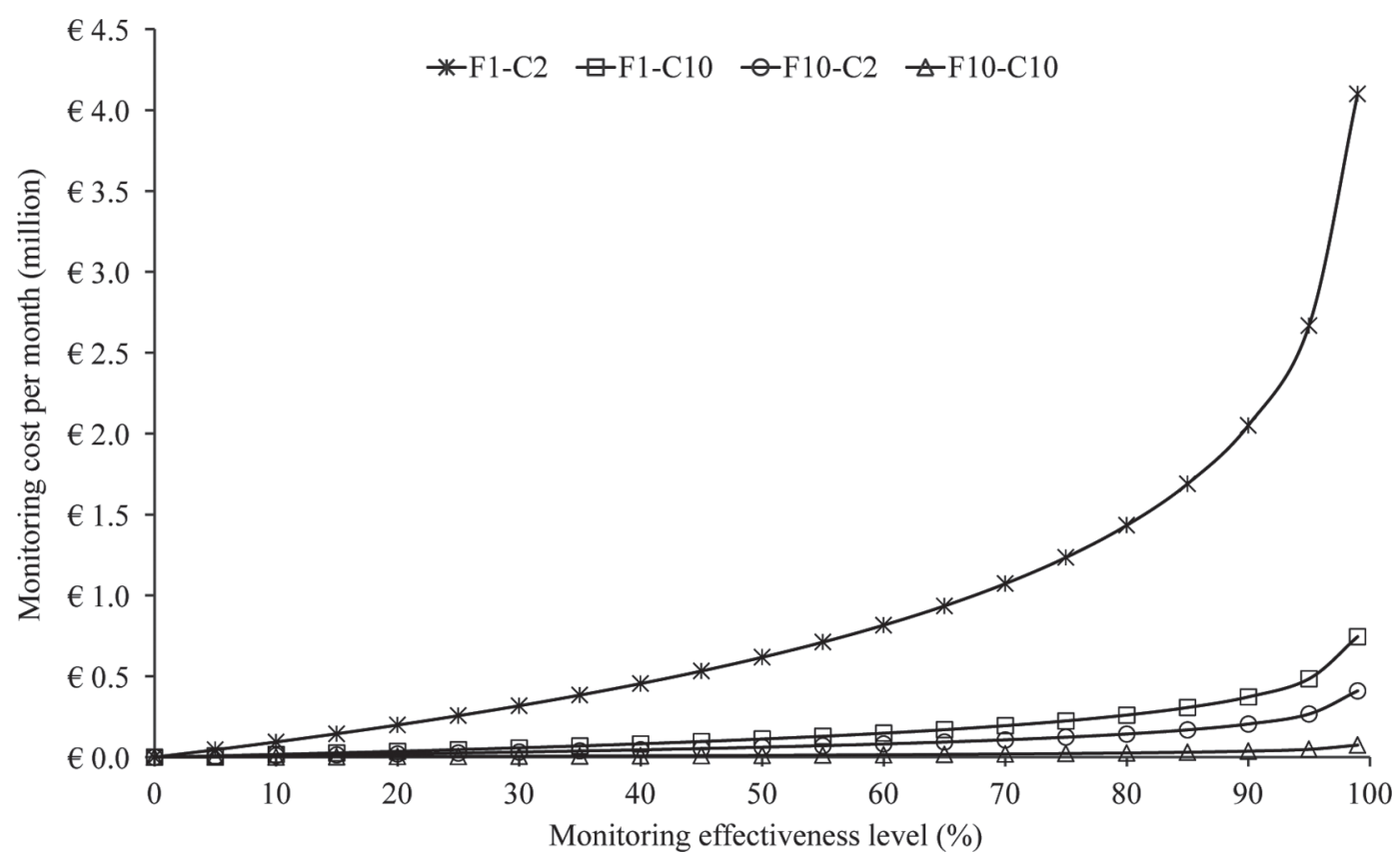

Figure 5. Effect of varying the level of monitoring effectiveness on the monitoring costs applied to 4 contamination scenarios. 


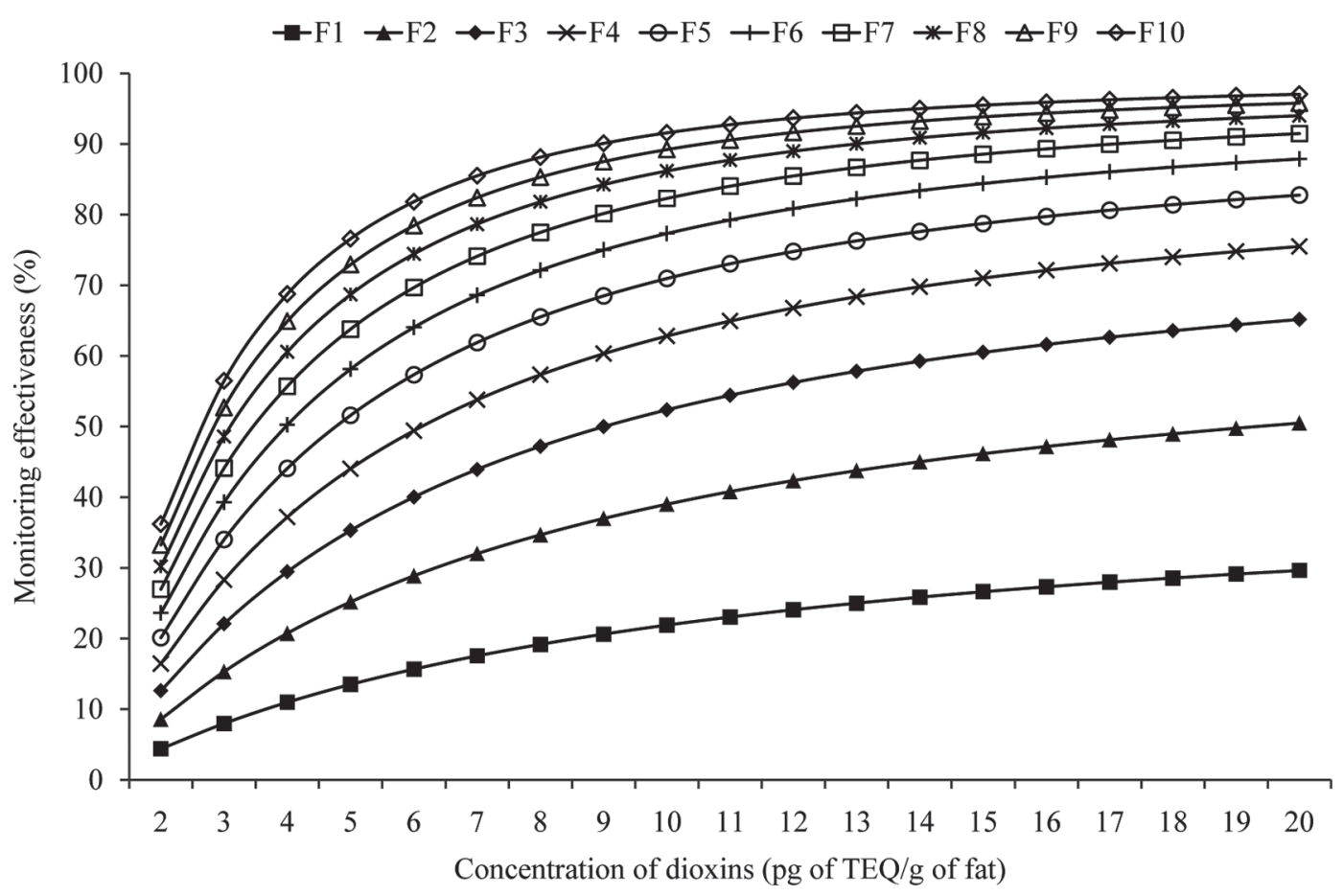

Figure 6. Maximum obtained effectiveness level for a monthly monitoring budget of $€ 40,000$ when increasing the expected number of contaminated farms (F1-F10) and the initial dioxin concentration at the farm level [2-20 pg of toxic equivalents (TEQ)/g of fat].

nated farm with a high level of effectiveness (90\%) and within detectable incidents of bigger proportions (F10$\mathrm{C} 10)$ is possible with relatively low monitoring budgets $(€ 50,000)$.

\section{DISCUSSION}

A linear programming methodology was used to build the MC and ME optimization models. Linear programming is a salient decision analysis method that undertakes resource allocation problems (Rushton, 2009) and ensures an optimal plan (Dijkhuizen and Morris, 1997). This methodology has been applied in previous studies to determine the optimal surveillance strategy when maximizing the efficacy of import phytosanitary inspection (Surkov et al., 2008, 2009) and to determine the optimal strategy to improve food safety at farm level in the Dutch dairy chain (Valeeva and Huirne, 2008).

The contextual scenario in which the dioxin monitoring and the contamination scenarios are described was built based on available information from the Dutch dairy chain. However, this study does not aim to be linked to the context of the dairy chain of a specific country, but to focus on presenting the methodology used to optimize dioxin monitoring in bulk milk within the context of a hypothetical dairy chain.
The losses of dairy farms or dairy processors related to mitigation strategies emplaced after an incident has been detected, such as the cost of destroying contaminated milk, are out of the scope of this study. The costs related to the effect of implementing mitigation strategies are direct financial costs (Lascano Alcoser et al., 2011) not related to the monitoring costs defined in this study.

By the MC and ME optimization models, this study established a relation between the costs of monitoring dioxins and the capacity of monitoring to detect an incident. These models can determine either the minimum amount of resources for monitoring needed to detect an incident with certain probability of detection (effectiveness), or the effectiveness from a given amount of resources. Establishing socially optimal levels of monitoring within the context of maximization of social welfare requires a more extensive analysis, including costs and benefits to government, industry, and consumers. The results of this study alone cannot be seen as an independent determinant of the socially optimal level of monitoring.

This study considers the EC maximum level of dioxins in milk (3 pg of TEQ/g of fat) and concentrations above this limit as hazard levels to public health. Milk contaminated with dioxin concentrations at or above maximum level is not allowed to be placed on the mar- 


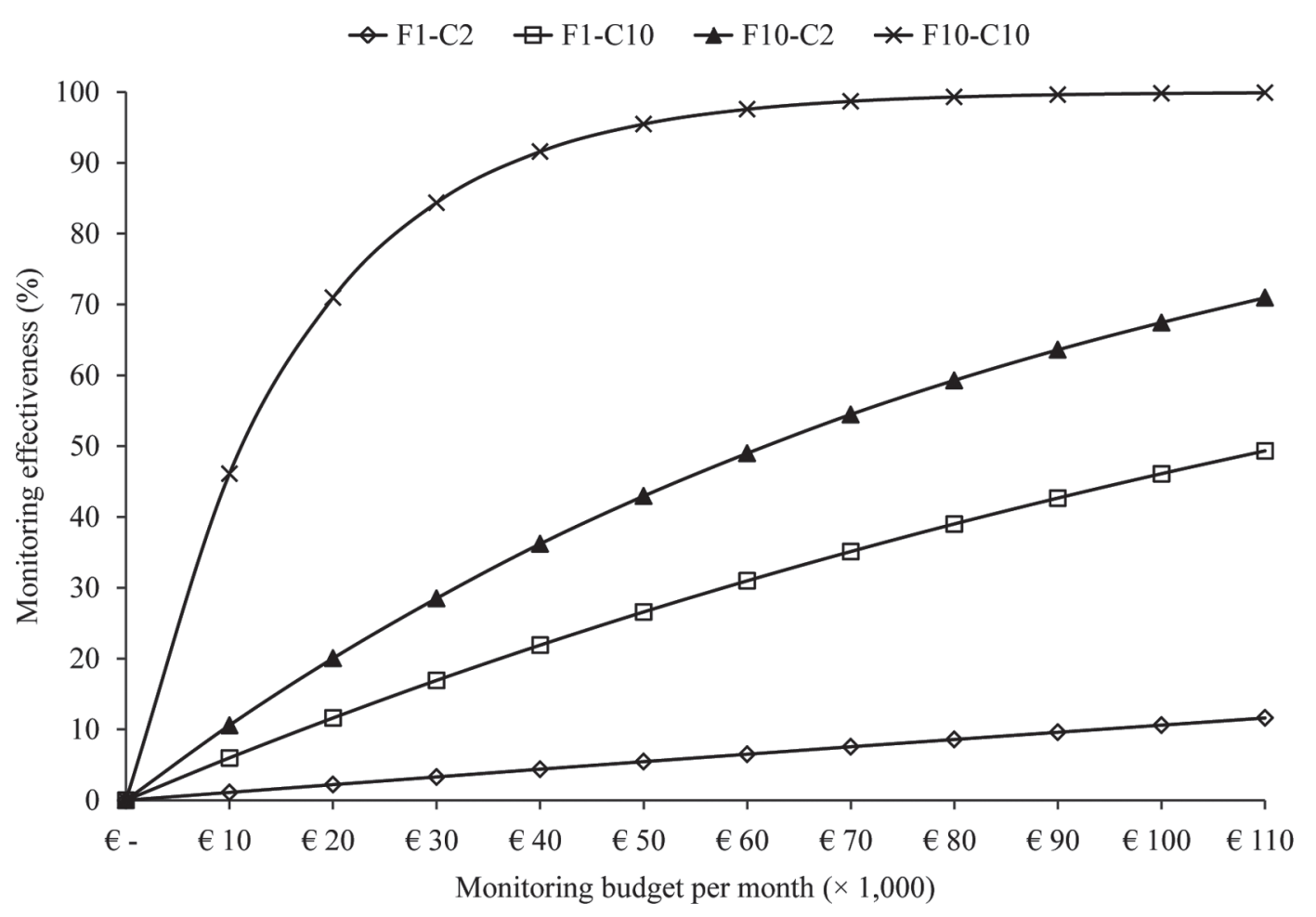

Figure 7. Levels of effectiveness for different monitoring budgets applied in 4 contamination scenarios.

ket (EC, 2006b). Dioxin concentrations tested below the maximum level and at or above the EC action level (2 pg of TEQ/g of fat) are considered warning signals of a potential incident. Therefore, they trigger further investigation to determine the source of the abnormal dioxin levels (EC, 2006a).

Detecting a dioxin incident with a high level of effectiveness is possible, but only at high costs. Monitoring costs and effectiveness are strongly determined by the size of the incident the monitoring is aiming to detect. The results of this study point to a large reduction in monitoring costs at the same level of effectiveness when aiming to find slightly larger detectable incidents than those in the reference scenario. For example, at the same level of effectiveness (95\%), a $73 \%$ reduction in monitoring costs was reached when aiming to detect 1 of 2 contaminated farms at the maximum level instead of 1 at the action level. This implies that dioxin monitoring aimed at detecting at least 1 contaminated farm among somewhat larger detectable incidents can be implemented at much lower costs without reducing the monitoring effectiveness level. Furthermore, our results show that low monitoring budgets are only highly effective when aiming to detect large incidents.

The decision to implement a specific dioxin monitoring plan given a certain budget or to reach a desired effectiveness level should be based on the level of risk accepted by the decision makers. Taking zero risk (zero tolerance), which means aiming to detect 1 contaminated farm at a bulk milk concentration equal to the action level, results in extremely high monitoring costs (€2.6 million per month at the $95 \%$ effectiveness level). This study showed that taking a higher risk for not detecting the smallest detectable incident significantly reduces the monitoring costs. However, the question remains as to how much risk is acceptable. In this regard, historical information with respect to the size of dioxin incidents could be used to identify the minimum acceptable risk. For example, when the Dutch milk dioxin incident occurred in 2004, only 1 contaminated farm was identified with a dioxin concentration of 20 pg of TEQ/g of fat (Hoogenboom et al., 2010). When applying the $\mathrm{MC}$ model, dioxin monitoring aimed at detecting an incident at this concentration with $95 \%$ effectiveness could be done with less than $10 \%$ of the monitoring costs required to detect an incident with a concentration equal to the action level. Moreover, most of the dioxin incidents frequently involve more than 1 contaminated farm, such as the 1998 dioxin incident in Germany in which milk from 2 dairy farms had an average dioxin concentration of $3 \mathrm{pg}$ of TEQ/g of fat (Malisch, 2000). In this case, the monitoring costs required to detect at least 1 of the 2 contaminated farms with a $95 \%$ effectiveness would be one-fourth of the cost required to detect this incident at the smallest target concentration considered in this research. In this 
regard, looking at the maximum level instead of the action level seems justifiable, but aiming at much higher levels seems more difficult to defend, as extremely high levels, such as $10 \mathrm{pg}$ of TEQ/g of fat or higher, are rarely observed. It can also be argued that incidents consisting of a single farm with concentrations around the maximum level may not be relevant, as this implies an extremely local source, the elimination of which may not contribute much to background levels.

In this study, the same decision limit was applied for both testing methods, Calux and HRGC/HRMS. In practice this could be different, because both methods could show different variations on the test results and different decision limits might be applied for each method. This would increase the accuracy of the results showed in this study. However, further research evaluating each of the methods should be carried out to determine better estimators of the decision limits for each method.

Pooling samples brings the possibility of getting false-positive results, thus, declaring certain a nonexistent incident. This is given that the same dioxin concentration at the positive pooled sample can be obtained by combining individual samples with different dioxin concentrations, none of them necessarily above the action level considered in this study. However, falsepositive results are not a concern to the objective of the monitoring, which is to detect an incident (given that it is certain) with a required effectiveness.

The average sampling cost per collected truck sample considered in this study is independent of the number of collected truck samples. Therefore, the relation between sampling costs and the number of collected samples is linear. However, as the capacity of the fixed factors associated to the sampling activity is reached, it is expected that the average cost per collected truck sample rises. For example, suppose that the capacity of the storage space to keep the collected truck samples is reached, then renting an extra storage space would be required and, thus, the average cost per collected truck sample would increase. Consequently, the total monitoring costs could have been underestimated as costs might increase when the number of collected truck samples increased. However, this assumption has a small effect on the results because the contribution of sampling costs is small compared with the contribution of test costs.

In this study, it was assumed that milk trucks were sampled randomly at each sampling time. This implies that milk from the same dairy farm might be sampled more than once per month. Therefore, the results of this study might vary if a different type of sampling procedure is applied (e.g., one where it can be assured that each farm is only tested once per month). This could be considered in further studies.

The pooling strategy of milk samples is highly important when the aim is to reduce the monitoring costs or increase the effectiveness of monitoring. However, the results of this research show that the possible cost advantage of mixing more truck or farm samples into a pooled sample is feasible to a limited extent. In fact, the maximum number of truck or farm samples that can be pooled depends on the target concentration aimed at detecting. Any pooling strategy mixing a bigger number of samples than the mentioned limit would dilute the concentration below the decision limit, compromising the possible detection of an incident. This is also the case when monitoring dioxins at other control points where a large number of trucks or farms are combined, such as at the silos at the entry of the milk processors. Additionally, if a contamination were detected at this control point, the incident costs aiming to identify the contaminated farm are expected to increase strongly. This is true given that a sample taken from a silo at the milk company could consist of milk from a large number of farms.

Further research should evaluate the cost and effectiveness of other monitoring strategies at other sampling points along the dairy chain. One of these strategies could be to monitor the feed or feed ingredients at the feed producer. Monitoring dioxins at this stage of the chain would be logical, given the importance of feed as one of the main sources of food dioxin contaminations (Buchert et al., 2001; Huwe, 2002). Additionally, monitoring at this stage of the chain could avoid the contamination of milk and the contamination of other agri-food chains. However, compliance of feed products to legal dioxin levels does not guarantee that dioxin levels in food products are not exceeded (van Raamsdonk et al., 2009). Minimum standard levels of dioxins in feed are required such that dioxin levels in food are not exceeded.

\section{CONCLUSIONS}

This study developed decision-making tools for risk managers of food industries and food safety authorities, to evaluate the costs and effectiveness of dioxin monitoring in bulk milk. The models developed can be used to determine the minimum amount of resources required to accomplish a certain level of effectiveness or to calculate the achieved level of effectiveness at a certain monitoring budget. To the knowledge of the authors no such models in the domain of food safety have ever been published. The optimal cost-effective dioxin monitoring depends on the monitoring goal, 
which at the same time depends on the level of risk (tolerance) that decision makers are willing to take. Taking zero risk (zero tolerance) results in extremely high monitoring costs; however, such incidents, caused by a local source of dioxins, may not contribute to the background level and may not be relevant. This study does not include costs and benefits of monitoring to government, industry, and consumers. Consequently, based only on the results of this study, it is not possible to determine optimal levels of dioxin monitoring that maximize social welfare. In all, the probability of detecting an incident largely depends on the number of truck samples collected. Thus, the sampling strategy can be improved by optimizing the number of collected truck samples, thereby ensuring an effective detection of an incident.

\section{ACKNOWLEDGMENTS}

This research was supported by RIKILT-Institute of Food Safety, Wageningen University and Research Center, Wageningen, the Netherlands. We kindly thank Wim Traag, Jaap Immerzeel, and Monique de Nijs (all from RIKILT-Institute of Food Safety, Wageningen University and Research Center) for their valuable input to this study.

\section{REFERENCES}

Bernard, A., F. Broeckaert, G. De Poorter, A. De Cock, C. Hermans, C. Saegerman, and G. Houins. 2002. The Belgian PCB/dioxin incident: Analysis of the food chain contamination and health risk evaluation. Environ. Res. 88:1-18.

Buchert, A., T. Cederberg, P. Dyke, H. Fiedler, P. Furst, A. Hanberg, J. Hosseinpour, O. Hutzinger, J. G. Kuenen, R. Malisch, L. L. Needham, K. Olie, O. Papke, J. Rivera Aranda, G. Thanner, G. Umlauf, T. Vartiainen, and C. van Holst. 2001. Dioxin contamination in food. Bayreuth, Germany. Sept. 28-Oct. 1, 2000. Environ. Sci. Poll. Res. 8(2):84-88.

De Mul, A., M. I. Bakker, M. J. Zeilmaker, W. A. Traag, S. P. J van Leeuwen, R. L. A. P. Hoogenboom, P. E. Boon, and J. D. van Klaveren. 2008. Dietary exposure to dioxins and dioxin-like PCBs in the Netherlands anno 2004. Regul. Toxicol. Pharmacol. $51: 278-287$.

Dijkhuizen, A. A., and R. S. Morris. 1997. Animal Health Economics, Principles and Applications. 1st ed. University of Sydney, Postgraduate Foundation in Veterinary Science. Sydney, Australia.

EC (European Commission). 2000. Report of experts participating in Task 3.2.5 "Assessment of dietary intake of dioxins and related PCBs by the population of EU Member States." In Reports on Tasks for Scientific Cooperation. European Commission, Health and Consumer Protection Directorate-General, Brussels.

EC (European Commission). 2001a. Communication from the Commission to the Council, the European Parliament and the Economic and Social Committe. Community Strategy for Dioxins, Furans and Polychlorinated Biphenyls. COM(2001) 593 final. Off. J. Eur. Comm. C 322:2-18.

EC (European Commission). 2001b. Council Directive 2001/102/EC of 27 November 2001 amending Directive 1999/29/EC on the undesirable substances and products in animal nutrition. Off. J. Eur. Comm. L 6:45-49.
EC (European Commission). 2001c. Council Regulation (EC) No 2375/2001 of 29 November 2001 amending Commission Regulation (EC) No 466/2001 setting maximum levels for certain contaminants in foodstuffs. Off. J. Eur. Comm. L 321:1-5.

EC (European Commission). 2002. Commission Recommendation 2002/201/EC of 4 March 2002 on the reduction of the presence of dioxins, furans and PCBs in feedingstuffs and foodstuffs. Off. J. Eur. Comm. L 67:69-73.

EC (European Commission). 2004. Commission Recommendation 2004/704/EC of 11 October 2004 on the monitoring of background levels of dioxins and dioxin-like PCBs in feedingstuffs. Off. J. Eur. Comm. L 321:38-44.

EC (European Commission). 2006a. Commission Recommendation 2006/88/EC of 6 February 2006 on the reduction of the presence of dioxins, furans and PCBs in feedingstuffs and foodstuffs. Off. J. Eur. Comm. L 42:26-28.

EC (European Commission). 2006b. Commission regulation (EC) No 1883/2006 of 19 December 2006 laying down methods of sampling and analysis for the official control of levels of dioxins and dioxinlike PCBs in certain foodstuffs. Off. J. Eur. Comm. L 364:32.

EC (European Commission). 2006c. Commission Regulation (EC) No. 1881/2006 of 19 December 2006 setting maximum levels for certain contaminants in foodstuffs. Off. J. Eur. Comm. L 364:5-24.

EFSA (European Food Safety Authority). 2010. Results of the monitoring of dioxin level in food and feed. EFSA J. 8:1385.

Frontline Systems Inc. 2011. Solver. Frontline Systems Inc., Incline Village, NV.

Heres, L., R. Hoogenboom, R. Herbes, W. Traag, and B. Urlings. 2010. Tracing and analytical results of the dioxin contamination incident in 2008 originating from the Republic of Ireland. Food Addit. Contam. Part A-Chem. 27:1733-1744.

Hoogenboom, R., M. Zeilmaker, J. van Eijkeren, K. Kan, M. Mengelers, D. Luykx, and W. Traag. 2010. Kaolinic clay derived PCDD/ Fs in the feed chain from a sorting process for potatoes. Chemosphere 78:99-105.

Huwe, J. K. 2002. Dioxins in food: A modern agricultural perspective. J. Agric. Food Chem. 50:1739-1750.

Huwe, J. K., and D. J. Smith. 2005. Laboratory and on-farm studies on the bioaccumulation and elimination of dioxins from a contaminated mineral supplement fed to dairy cows. J. Agric. Food Chem. 53:2362-2370.

Kan, C. A., and G. A. L. Meijer. 2007. The risk of contamination of food with toxic substances present in animal feed. Anim. Feed Sci. Technol. 133:84-108.

Lascano Alcoser, V. H., A. G. J. Velthuis, L. A. P. Hoogenboom, and H. J. van der Fels-Klerx. 2011. Financial impact of a dioxin incident in the Dutch dairy chain. J. Food Prot. 74:967-979.

Malisch, R. 2000. Increase of the PCDD/F-contamination of milk, butter and meat samples by use of contaminated citrus pulp. Chemosphere 40:1041-1053.

Rushton, J. 2009. The Economics of Animal Health and Production Foreward by P. Ellis with contributions from A. James, A. Shaw, D. Leonard, C. Tisdell, J. Otte, A. Stott, H. Rojas, P. Bonnet, C. Devendra, L. Redmond, H. Beck, U. Pica-Ciamarra, M. Lesnoff, V. Ahuja, and M. Upton. CABI Publishing, Wallingford, UK.

SCF (Scientific Committee on Food). 2001. Opinion of the Scientific Committee on Food on the risk assessment of dioxins and dioxin-like PCBs in food. Scientific Committee on Food report CS/ CNTM/DIOXIN/20 final. Accessed Apr. 2012. http://ec.europa. eu/food/fs/sc/scf/out90_en.pdf

Schmid, P., E. Gujer, S. Degen, M. Zennegg, A. Kuchen, and C. Wuthrich. 2002. Levels of polychlorinated dibenzo- $p$-dioxins and dibenzofurans in food of animal origin. The Swiss dioxin monitoring program. J. Agric. Food Chem. 50:7482-7487.

Surkov, I. V., A. G. J. M. Oude Lansink, and W. van der Werf. 2009 The optimal amount and allocation of sampling effort for plant health inspection. Eur. Rev. Agric. Econ. 36:295-320.

Surkov, I. V., A. G. J. M. Oude Lansink, O. van Kooten, and W. van der Werf. 2008. A model of optimal import phytosanitary inspection under capacity constraint. Agric. Econ. 38:363-373. 
UNEP (United Nations Environment Program). 2009. Stockholm Convention on persisten organic pollutants (POPs) as amended in 2009. Text and Anexes. United Nations Environment Program. Accessed June 2012. http://chm.pops.int/Convention/ConventionText/tabid/2232/Default.aspx.

Valeeva, N. I., and R. B. M. Huirne. 2008. Strategies to improve food safety in the dairy chian: A case-study from the Netherlands. Opportunities and Challenges for Smallholder Ruminant Systems in Latin America. Universidad Autonoma Estado Mexico, Toluca, Mexico. van Raamsdonk, L. W. D., J. C. H. van Eijkeren, G. A. L. Meijer, M. Rennen, M. J. Zeilmaker, L. A. P. Hoogenboom, and M. Mengelers. 2009. Compliance of feed limits, does not mean compliance of food limits. Biotech. Agron. Soc. 13:51-57.

Velthuis, A. G. J., M. P. M. Meuwissen, and R. B. M. Huirne. 2009. Distribution of direct recall costs along the milk chain. Agribusiness 25:466-479.

WHO (World Health Organization). 2007. Dioxins and their effects on human health. Fact sheet 225. World Health Organization, Geneva, Switzerland. 